\title{
TRABALHO DOCENTE: A DINÂMICA ENTRE FORMAÇÃO, PROFISSIONALIZAÇÃO E PROLETARIZAÇÃO NA CONSTITUUIÇÃO DA IDENTIDADE
}

\author{
Claudia Barcelos de Moura Abreu* \\ Sonia Regina Landini ${ }^{*}$
}

\section{Resumo}

Este artigo tem por objetivo discutir como a natureza do trabalho docente e sua identidade devem ser pensadas como experiência concreta das relações sociais. Nesta discussão, é dada especial atenção às questões concernentes às condições universais e como os professores, em sua singularidade, estabelecem mediações que refletem suas reais condições de trabalho. Neste contexto, a dinâmica entre proletarização, profissionalização e formação devem ser analisadas pela ambigüidade que tem se processado historicamente. Essa reflexão nos leva a considerar, de um lado, o status do professor como necessário ao capital e, por outro lado, as reivindicações da categoria dos professores na direção de políticas que assegurem melhores condições de trabalho, identificadas na vivência cotidiana, na própria condição de exploração, na perda da autonomia, na precarização das condições de trabalho, ou seja, de suas práticas sociais.

Palavras-chave: Trabalho docente, Proletarização, Profissionalização, Ontologia, Dialética singular-particular-universal.

\section{Abstract}

This paper aims to discuss how the nature of the teaching work and its identity must be thought as the concrete experience of the social relations. In this discussion, special attention is given to the questions concerning the universal conditions and how teachers, in theirs singularity, establish mediations that reflect theirs real conditions of work. In this context, the dynamics between proletarization, profissionalization and formation must be analyzed by the ambiguity that has been processed historically. This

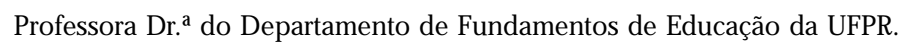

E-mail: claudiabarcelos@ufpr.br

* Pesquisadora recém-doutora - CNPq/Setor de Educação - UFPR.

E-mail: sonialandini@ig.com.br

Endereço: Rua: Governador Agamenon Magalhães, n. ${ }^{\circ} 199$ ap to 53 , Cristo Rei, Curitiba- PR, CEP 80050-510. 
reflection leads to consider, by the one hand, the teacher's status as necessary to capital and, by the other hand, the claims of the teacher's category in yhe direction of politics that assure better conditions of work, which can be identified in the daily experience, the proper condition of exploration, the loss of the autonomy, the precarization of the work conditions, what means, its social practice.

Keywords: Teatcher's work, Proletarization, Profissionalization, Ontology, Singular-particular-universal dialectic.

O trabalho docente no atual momento histórico é resultado de modificações importantes e profundas...

A discussão sobre a natureza capitalista deste trabalho não foi resolvida e necessita não só de mais estudos teóricos (...) como também de mais estudos empíricos sobre o cotidiano do trabalho docente, articulados com uma visão macrossocial e econômica de caracterização sociológica dessa atividade de trabalho.

(Hypolito)

As discussões acerca do trabalho docente, apesar de não serem recentes, nos colocam a reincidente questão sobre sua natureza, em especial considerando-se as transformações ocorridas nas últimas décadas no mundo do trabalho e na sociedade em geral, bem como o modo pelo qual se constitui a identidade do trabalhador-professor.

A especificidade do trabalho docente, não-material, traz à tona reflexões sobre o papel deste tipo de trabalho na sociedade capitalista e de como este papel toma forma na construção da identidade docente.

Saviani (1983), em sua preciosa contribuição, ao discutir o trabalho docente recorre a Marx, caracterizando o trabalho não-material sob duas formas: a primeira refere-se a mercadorias que existem isoladamente em relação ao produtor, como os livros, obras artísticas, etc., ou seja, mercadorias que circulam entre ato de produção e consumo; a segunda, diz respeito à atividade, na qual produção e consumo são concomitantes, como no caso do médico, do professor, etc. ${ }^{1}$

Neste contexto, o trabalho docente está relacionado à lógica capitalista de produção apenas limitadamente. "(..) .em razão da característica inerente ao ato pedagógico, o modo de produção capitalista não se dá aí, senão em algumas esferas." (SAVIANI, 1984, p.81) ${ }^{2}$

Dessa perspectiva, o trabalho do professor, tendo como produto 0 saber, pode ser compreendido como não produtivo na medida em que não está diretamente vinculado à produção de mais-valia. No entanto, é preciso considerar que Mar ao refletir sobre o trabalho produtivo e o trabalho improdutivo evidencia que, de fato, não importa se o trabalhador produz bens 
materiais ou serviços, mas sim o resultado do trabalho no processo de valorização do capital.

Do ponto de vista do processo de trabalho em geral, apresentava-se como produtivo aquele trabalho que se realizava num produto, mais concretamente numa mercadoria. Do ponto de vista do processo capitalista de produção, junta-se uma determinação mais precisa: é produtivo aquele trabalho que valoriza diretamente o capital, o que produz mais-valia... (MARX, 1985, p.109, grifos do autor).

Outro aspecto a ser considerado é que entre os traços que caracterizam o modo capitalista de produção está o fato do trabalhador vender sua capacidade de trabalho em troca de um salário, ou seja, ser trabalhador assalariado. Além disso, o trabalho docente incorpora-se no processo de produção do capital, convertendo-se na sua componente variável. Isto significa que 0 trabalho docente, assalariado, está atrelado à produção de mais-valia na medida em que está vinculado à formação da força de trabalho. Neste sentido, ainda que não diretamente produtivo, o trabalho do educador e do professor estão vinculados à lógica produtiva. ${ }^{3}$

Marx também observa que, com o desenvolvimento do modo de produção capitalista e a subsunção real ${ }^{4}$ do trabalho ao capital, cada vez mais aumentam as "... funções da capacidade de trabalho incluídas no conceito imediato de trabalho produtivo."(MARX, 1985, p.110, grifos do autor)

Seguindo esta linha de raciocínio, seria relevante observar que na subsunção formal do trabalho ao capital há produção de mais-valia e sua apropriação por parte do capital, mas as condições objetivas e subjetivas do trabalhador favorecem a uma resistência contínua, à imposição da valorização como o objetivo exclusivo do processo de produção. Isto significa que, a despeito das condições já existentes de extração de mais-valia, existe ainda uma relação "(...) entre o trabalhador e as condições de trabalho no interior da produção, que dão ao trabalhador um certo grau de controle e, portanto, um instrumento com o qual pode fazer valer seus objetivos de classe". (BRIGHTON GROUP. Apud de SILVA, 1991, p.19). Com a subsunção real do trabalho, cada vez mais a lógica capitalista se dissemina ao longo da cadeia produtiva, perpassando setores não necessariamente produtivos, mas que interferem no conjunto da produção e do consumo. No caso do trabalho docente, um dos papéis que assume, dentro da lógica capitalista e da subsunção real, é a de preparar os alunos para o mundo produtivo, quer da perspectiva da produção, como a do consumo,sem que tenha domínio sobre o processo de construção e elaboração do conhecimento. Além disso, é preciso notar que as condições de trabalho do professor refletem a realidade do trabalho na sociedade capitalista, marcada por mediações, conquistas e derrotas da classe trabalhadora por melhores condições de trabalho e vida. Nesse sentido, o 
salário do professor é também regulado pelo trabalho assalariado em geral, pelo valor socialmente definido da força-de-trabalho. ${ }^{5}$

Assim, é importante considerarmos que:

a. O processo capitalista de produção é um processo que absorve trabalho não pago, que transforma meios de produção em meios para sugar trabalho não pago, valor excedente. Então, trabalho material ou imaterial podem, ambos, estar vinculados ao processo de produzir mais-valia;

b. É o processo de produção de mais-valia que caracteriza o trabalho como produtivo;

c. Ainda que um trabalho determinado não esteja imediatamente vinculado ao processo de mais-valia, ele precisa ser considerado a partir de seu papel na lógica de valorização do capital. Ou seja, no papel que ocupa na reprodução social, o que o coloca, ainda que indiretamente, como parte do processo de constituição dos mecanismos de produção e acumulação do capital.

Partindo destas reflexões, podemos analisar o trabalho docente no decurso do desenvolvimento capitalista, tendo em vista as transformações ocomidas no último quartel do século XX, momento em que há uma crescente tendência à terciarização da economia, com a valorização do setor de serviços como fonte de exploração e acumulação de capital. ${ }^{6}$

Sabemos que os professores das escolas públicas têm alguns diferenciais com relação aos das escolas privadas, na medida em que são menos explicitamente expostos à exploração de mais-valia. No entanto, é importante ressaltar que o Estado capitalista, como instrumento da classe dominante, não poderia impor outra lógica a seus próprios funcionários que não a lógica capitalista de produção, ainda que o trabalho do funcionário público não esteja vinculado diretamente ao processo produtivo. Além disso, é importante observar que os processos de reprodução, para além do controle coercitivo do Estado, se processam também por meio de instituições presentes na sociedade civil, entre as quais a escola.

Carnoy (1993) chama atenção para o fato de que a educação, parte do aparelho de Estado, contribui para a reprodução da estrutura de classes por meio da qualificação profissional e inserção dos jovens no mercado de trabalho, além de ser fonte de inculcação ideológica. Ainda, ao evidenciar os escritos de Poulantzas (1975), chama atenção para o fato de que o aparelho educacional se constitui em

(...) fonte de emprego de grupos subalternos da sociedade [e], no capitalismo monopolista avançado, os professores e administradores do sistema escolar fazem parte da 'nova pequena burguesia', que provém de setores da classe trabalhadora e oferece mobilidade ascendente para mulheres e membros masculinos de minorias. (CARNOY, 1993, p. 69). 
Os professores, membros da classe trabalhadora, ingressam na carreira motivados pela possibilidade de emprego, já que pertencem a grupos subalternos, nem sempre privilegiados pelo mercado de trabalho, assumindo os valores da classe dominante. O Estado, ao contratar seus funcionários, "educa-os" para que se identifiquem com a classe que domina o Estado, distanciando-se da sua condição originária de classe. ${ }^{7}$

Quanto mais a sociedade se complexifica, mais importante é o papel da educação. Ao mesmo tempo, quanto mais o trabalho se subsume realmente à lógica do capital, mais ele se parcelariza, e maior a distância entre planejamento e execução. A escola tende a incorporar estes pressupostos administrativos e organizativos, não tanto pelo conteúdo do que ensina, mas muito mais pelos valores que transmite. Deste modo, como funcionário da escola pública, o professor se vê submetido aos organismos que pensam e planejam a educação, ao delegado de ensino, à direção, etc., e, como trabalhador, se submete ao poder exercido de cima para baixo. Este quadro coloca o professor na posição de trabalhador, que tem cerceada sua liberdade de trabalho, como ser autônomo e criativo.

Neste quadro, podemos analisar as condições de trabalho relativas ao setor de serviços, no qual se inclui o trabalho do professor.

Braverman (1987, p. 299-300) irá apontar, tendo como base os escritos de Marx, um movimento de proletarização do trabalho em serviços, com constante perda sobre o domínio do processo de trabalho, associado à desqualificação, considerando-o como parte integrante dos mecanismos de valorização do capital. A tendência pode ser evidenciada, segundo o autor, a partir do fato de que "(...).uma ampla classe média não proletária voltou-se à criação de um vasto proletariado sob nova forma. Em suas condições de emprego esta população trabalhadora perdeu todas as antigas superioridades sobre os trabalhadores fabris, e em suas escalas de salários desceu quase ao nível mais baixo".

Na mesma linha de raciocínio, Sá (1986) defende a existência de um movimento de proletarização do trabalho docente. Entre seus argumentos, o autor ressalta as mudanças no sistema de ensino, acompanhando as mudanças no modo capitalista de produção, no qual se observa uma divisão do trabalho docente, retirando do professor a propriedade de seu meio de produção, o conhecimento. É fato que Marx, ao descrever o trabalho no setor terciário, o faz no contexto histórico de centralidade do trabalho operário, da industrialização, sem que houvesse um processo claro de divisão do trabalho no setor. Tomando a historicidade das relações capitalistas de produção, devemos considerar os mecanismos de autovalorização do capital, os quais incluem mudanças nas formas de organização da produção e do trabalho, tendo como uma de suas características a crescente terceirização da economia. 
Em similar linha de raciocínio, Apple (1987;1989) enfatiza que o professor tem cada vez menos domínio sobre o produto de seu trabalho. $\mathrm{O}$ tempo para pensar, planejar, etc., tem sido cada vez menor, marcado pela distinção entre pensar e fazer. Neste sentido, ocorre uma fragmentação do trabalho docente, tese esta também enfatizada por Santos (1989, p. 27) ao descrever a parcelarização do trabalho docente, separando-se, de um lado, professores e, de outro lado, especialistas em educação. "Há, portanto, uma cisão entre trabalhadores do ensino e a organização do processo de trabalho."

Sà (1986, p. 22), por sua vez, também considera a necessidade das análises sobre 0 trabalho docente valorizarem "(...)o modo pelo qual os homens produzem sua existência". Nesse sentido, afirma que a divisão do trabalho educacional tem como características a “(...) parcelarização do trabalho pedagógico ou desagregação da autoridade pedagógica do professor artesão. Tal desagregação significa, ao mesmo tempo, a exploração do saber concentrado no professor e sua localização no capital ou nas empresas estatais. É dessa característica que resulta a constante 'desqualificação' ou 'incompetência' do professor" (ibidem, p. 25).

O autor rebate a tese de Saviani (1983) a respeito da ação pedagógica ser dotada de uma natureza e especificidade que a impede de submeter-se à lógica da relação capitalista. Para fundamentar essa afirmação, Sá afirma que Saviani faz uma leitura de Marx que não acompanha o desenvolvimento do modo de produção capitalista o que o impede de perceber o movimento da sociedade que busca, ao longo do tempo, ir incorporando à sua lógica todos os setores e instituições da sociedade, ou seja, passar da subordinação formal do trabalho ao capital para a subordinação real.

É possível, nessa perspectiva, considerar o fato de que o trabalho docente, no quadro de sua proletarização, tem associado como fator de complexificação a condição de sua profissionalização. A profissionalização docente é tema recorrente na literatura especializada e a base de muitas das reivindicações dos professores.

Enguita (1991) define a profissionalização pela competência específica, pela vocação, pela auto-regulação e pela independência.

Freitas (1992, p. 8-9), por sua vez, define os agentes envolvidos com a escola como trabalhadores da educação, no entanto, estes não são necessariamente profissionais da educação. Para o autor, não é o local de trabalho que define uma profissão, mas sim "(...)as relações para as quais os profissionais são preparados". E conclui que educador é aquele que:

(...)tem a docência como base de sua identidade profissional; domina 0 conhecimento específico de sua área, articulado ao conhecimento pedagógico, numa perspectiva de totalidade do conhecimento socialmente produzido, que lhe permite perceber as relações existentes entre as atividades 
Trabalho docente: a dinâmica entre formação, profissionalização e proletarização na ...

educacionais e a totalidade das relações sociais em que o processo educacional ocorre; é capaz de atuar como agente de transformação da realidade na qual se insere. $^{8}$

No processo de subsunção real do trabalho ao capital, a prática social docente se estabelece de modo que a capacidade de se colocar criticamente frente à realidade se contrapõe à perda de controle, de autonomia, caracterizando uma intensa diminuição no processo de profissionalização.

O domínio de conhecimentos, habilidades e competências torna-se, deste modo, a principal fonte de preocupação e proposições para reversão desse quadro caótico. Neste sentido, tendo em vista a melhoria do estatuto da categoria, o aumento do poder, controle e autonomia no processo de trabalho, a defesa da profissionalização docente por meio dos processos formativos torna-se fonte de estudos teóricos e empíricos. A formação docente, portanto, toma corpo como saída para a realidade posta.

Nessa linha de raciocínio podemos incluir os estudos de Novoa (1992), Schon (2000), Perrenoud (1993), os quais defendem os processos formativos baseados na reflexão na ação, reflexão sobre a ação, reflexão sobre a reflexão na ação (SCHÖN, 2000). Para esses autores, os professores necessitam dominar o processo de trabalho, o que só se faz possível a partir da experiência compartilhada, da reflexão sobre sua prática e sobre sua própria reflexão, superando valores e limites postos pelas relações de poder que legitimam as desigualdades sociais. A experiência reflexiva é, nesse caso, o cerne da formação e da profissionalização.

Não pretendemos esgotar neste artigo estas proposições. Nos interessa evidenciar a dinâmica entre formação, profissionalização e proletarização na constituição da identidade.

Tomando como referência a tese da proletarização docente, por um lado, e, por outro lado, a profissionalização vinculada à formação, temos que a última possibilita, teoricamente, uma gama de conhecimentos que podem ser considerados como instrumentos na luta contra a proletarização. No entanto, considerar a formação como alternativa para a luta contra a proletarização docente pode nos levar a assumir uma postura idealista, descolando a formação do quadro geral das contradições postas na sociedade.

No quadro do capitalismo mundializado e das políticas neoliberais, a natureza do trabalho docente e a identidade docente devem ser pensadas como a vivência concreta das relações sociais.

No jogo de forças presentes nas relações sociais (e que as compõem) estão as conquistas, alianças, etc., travadas entre as classes sociais, buscando a hegemonia. Neste contexto, entram em cena os intelectuais, aos quais, na qualidade de intelectuais orgânicos, cabe a tarefa de estimular a tomada de consciência da classe à qual pertencem. Neste cenário, uma das questões a ser 
investigada diz respeito a estarem ou não os professores das escolas públicas assumindo seu papel. Qual a consciência possível e posta que o professor possui com relação à classe a qual pertence?

Neste sentido, a análise sobre a identidade docente nos leva ao necessário questionamento acerca das condições universais e, em que medida os professores nas suas práticas singulares, estabelecem mediações que refletem o quadro geral de proletarização, mas que também trazem à tona as demandas por profissionalização.

Deste modo, compreendemos que investigações sobre a identidade docente nos impõem a necessidade imperativa de um método capaz de captar a relação dialética entre singularidade-particularidade-universalidade.

Para melhor compreender estas questões, na especificidade da educação escolar e do trabalho docente no capitalismo mundializado, tendo como referência as contribuições de Lukács (1968, 1981), podemos dizer que ao se valorizar o papel da formação no processo de profissionalização docente, devemos nos preocupar com aspectos contraditórios, tais como: a formação como momento de desalienação, sem que as práticas sociais o sejam; a formação como isenta da lógica de reprodução capitalista; o professor como singular, como sujeito que se constitui apenas pela sua formação. Ou seja, ao se idealizar a formação (escolar, em serviços, etc.), acaba-se por isolá-la das condições concretas que, na conjuntura atual, serve tanto para reproduzir o sistema quanto para instrumentalizar os professores na luta contra a proletarização.

Em outra medida, ao valorizarmos exageradamente as condições sociais postas, podemos divinizar a realidade, sem que consigamos apreender os mecanismos de reação, resistência e negação frente à ela. Em ambos os casos, a autonomização - quer do universal, quer do singular - leva a uma análise que desvaloriza a dinâmica própria da realidade social que, em sua constituição contraditória, é reflexo e, ao mesmo tempo, reflete as necessidades humanas, bem como a expropriação das condições de alcance destas necessidades.

Em Lukacs (1981) podemos compreender o homem como ser social, que se constitui na relação concreta (prática social) em que, objetivando 0 alcance de um fim determinado (posição teleológica), cria mecanismos, estabelece mediações, escolhe entre as opções postas (alternativa) a que melhor condiz com o resultado esperado. Nesse contexto, no trabalho está contido um processo que o autor denomina reflexo da realidade na consciência, ou seja, a realidade - existente, concreta, síntese das ações humanas historicamente constituídas - é captada pelo sujeito e por ele apreendida como reflexo, tendo em vista sua trajetória histórica. A realidade, refletida na consciência, é, pois, a síntese dialética entre a realidade objetiva e o sujeito.

O ser social, ao se deparar com a realidade que o cerca, contém em si parte desta realidade, ao mesmo tempo em que nela está contido. Universal 
e singular estabelecem mediações que se expressam na forma do particular, ou seja, na posição que ocupam na totalidade das relações sociais. Assim, podemos sintetizar esta complexa análise na posição que o ser social ocupa no desenvolvimento do trabalho, o que na sociedade capitalista significa dizer sua condição de classe.

Assim, uma análise dialética pressupõe que se extraia

(...)da própria realidade as condições estruturais e suas transformações histónicas e, se [formule] leis..[ as quais abracem] a universalidade do processo, mas de um modo tal que deste conjunto de leis pode-se retornar - ainda que freqüentemente através de muitas mediações - aos fatos singulares da vida. (LUKÁCS, 1968, p. 88)

No caso do trabalho docente é preciso considerar as práticas sociais dos sujeitos envolvidos, nesta categoria, a partir de sua formação escolar, do contexto social em que essa formação se põe, da vivência cotidiana na escola, das relações que estabelece com o produto de seu trabalho - o saber -, das relações com outros agentes educacionais envolvidos na escola, da relação que estabelece com o sindicato e as instituições representativas de classe, das condições estruturais da profissão (salário, condições de trabalho, etc.), entre outros fatores.

Nesse sentido, se o processo de proletarização docente é uma realidade inerente ao modo de produção capitalista e suas transformações, também o é a profissionalização docente.

A identidade docente se constitui nesse âmbito de mediações, do qual podemos concluir que nem a formação, nem a experiência individual, nem as políticas públicas têm, isoladamente, papel determinante na definição do caráter identitário. Somente a investigação dialética entre essas esferas pode permitir que captemos os desejos de emancipação, os mecanismos de cooptação e reprodução sociais e, neste conflito, aquilo que determina a identidade docente neste momento histórico.

\section{Notas}

1 Segundo MARX (1985, pp. 119-120) "No caso da produção não material, mesmo quando é efetuada com vista exclusivamente à troca e mesmo que crie mercadorias, existem duas possibilidades: 1) o seu resultado são mercadorias que existem separadamente do produtor, ou seja, podem circular como mercadorias no intervalo entre produção e consumo, por exemplo, livros, quadros, todos os produtos artísticos que existem separadamente da atividade artística do seu criador e executante. A produção capitalista só se pode aplicar aqui de maneira muito limitada. (...) 2) O produto não é separável do ato da produção. Também aqui o modo capitalista de produção só tem lugar de maneira muito limitada, e só pode tê-lo, devido à natureza da coisa, em algumas esferas. (Necessito de médico e não do seu menino de recados). Nas instituições de ensino, por exemplo, para o empresário da fábrica de conhecimentos os docentes podem ser meros assalariados.Casos similares não devem ser tidos em conta quando se analisa o conjunto da produção capitalista." 
2 Assim como Saviani, HYPÓLITO (1997), SILVA (1991), PARO (1986) consideram questionáveis as teses de proletarização do trabalho docente por não se caracterizarem efetivamente vinculadas à lógica da economia capitalista, por não produzirem mais-valia e possuírem uma especificidade própria: o produto do trabalho - o saber - não ser submetido à relação capitalista de produção de mais-valia.

3 MARX (1985, p.134) chama atenção para a 'criação de assalariados', o que nos remete aos processos educativos, incluindo a educação escolar e o professor. $\mathrm{O}$ autor salienta que o processo de acumulação implica numa “(...) nova 'criação de assalariados', que são meios para a realização e o incremento do capital existente, já porque subsume neles parte da população ainda não abrangida pela produção capitalista, tais como as crianças e as mulheres, já porque, graças ao crescimento natural da população, se lhe submete uma massa acrescida de operários".

4 Subsunção formal, para Marx, consiste no fato de estarem os trabalhadores vinculados à lógica capitalista, mantendo no entanto, domínio sobre suas ações, com menor divisão do trabalho e participação no processo de produção de modo menos parcelar. Para se aumentar a mais-valia, neste caso, aumentase a jornada de trabalho. No caso da subsunção real, há um parcelamento do trabalho, com a perda do domínio do processo de trabalho por parte dos trabalhadores. A tecnologia, em diversos casos, incorpora parte do saber dos trabalhadores. O processo de trabalho é inteiramente dominado e incorporado pelo Capital.

5 Chamamos atenção para o fato de que para produzir mais-valia mediante a transformação do trabalho necessário em mais trabalho tem que se revolucionar as condições técnicas e sociais do processo de trabalho.Portanto o próprio modo de produção, a fim de aumentar o lucro por meio da força produtiva do trabalho, procura reduzir o valor da Força de Trabalho que determina o tempo necessário para a reprodução de seu valor. $\mathrm{O}$ valor das mercadorias, por sua vez, está na razão inversa da força produtiva do trabalho, do mesmo modo que, por ser determinado por valores de mercadorias, está o valor da Força de Trabalho. Ou seja, quando se diminuem os preços das mercadorias (em razão de mudanças técnicas e organizacionais) diminui também o valor médio que o trabalhador precisa para se reproduzir, o que gera uma desvalorização da mão-de-obra.Por isso, é impulso imanente e tendência constante do capital aumentar a força produtiva do trabalho para baratear a mercadoria e, mediante o barateamento da mercadoria, baratear o próprio trabalhador.

6 Para compreender estas transformações ver Harvey (1994); Chesnais (1995).

7 Snyders (1976) chama atenção para o fato de que um grande número de docentes, muitas vezes, vindos da classe média ou que compartilham seus hábitos e gostos, vivem na confusão das situações contraditórias, pois ora se ligam à grande burguesia, ora lhe resistem. Por isso, muitas vezes, a classe média pode aderir a posições da classe operária como uma medida preventiva, ou seja, defendem algo para que mais tarde não venham a se tornar proletários.

8 Nota do autor: Anfope (1989, p.13). Por "docência" entenda-se "trabalho pedagógico".

\section{Referências}

APPLE, M . Educação e Poder. Porto Alegre: Artes Médicas, 1989.

. Relações de classe e gênero e modificações no processo de trabalho docente. Cadernos de Pesquisa, São Paulo, n. 60, p.3-14. fev. 1987.

BRAVERMAN, $\mathrm{H}$. Trabalho a capital monopolista: a degradação do trabalho no século XX. 3 ed. Rio de Janeiro, 1987. 
BRIGTHON LABOUR PROCESS GROUP. O processo de trabalho capitalista. In SILVA, T.Tadeu da.(org.) Trabalho, educação e prática social. Porto Alegre: Artes Médicas, 1991.

CARNOY. M. Escola e Trabalho no Estado capitalista. 2 ed. São Paulo: Cortez, 1993.

CHESNAIS, F. A mundialização do capital. São Paulo: Xamã, 1995.

CARNOY. M. Escola e Trabalho no Estado capitalista. 2 ed. São Paulo: Cortez, 1993

CHESNAIS, F. A mundialização do capital. São Paulo: Xamã, 1995

ENGUITTA,M. F. A ambigüidade da docência: entre o profissional e a proletarização. Teoria \& Educação, n.4, p.41-61, 1991.

FREITAS.L.C. . Em direção à uma Política de formação de professores. Em Aberto, n. 54, 1992.

HARVEY, D. A condição pós-moderna. São Paulo: Loyola, 1994

HYPÓLTO, A. M. Trabalho docente, classe social e relações de gênero. Campinas: Papirus, 1987.

LUKÁCS, G. Introdução a uma Estética Marxista: sobre a categoria da particularidade. Rio de Janeiro: Civilização Brasileira, 1968.

LUKÁCS, G. Per L'Ontoligia del'Essere Sociale. Roma: Riuniti, 1981. v. 2. tomo 1.

MARX, K.. O Capital. São Paulo: Moraes, 1985. Cap. 6.

NÓVOA, A (Coord.) Os professores e a sua formação. Lisboa: Publicações Dom Quixote, 1992.

PARO,V.H. Administração escolar: introdução crítica. São Paulo: Cortez, 1986

PERRENOUD, P. Práticas pedagógicas, profissão docente e formação. Lisboa: Dom Quixote, 1993.

POULANTZAS, N. Política Power and social class“.London:New Left Books, 1974, In: CARNOY.M. Escola e Trabalho no Estado capitalista. 2 ed. São Paulo: Cortez, 1993.

SÁ, Nicanor P. Aprofundamento das relações capitalistas no interior da escola. Caderno de Pesquisa, São Paulo, n.57, p.20-29, maio 1986. 
SANTOS, Oder J.dos. Organização do processo de trabalho docente: uma análise crítica. Educação em Revista, Belo Horizonte, n. 10, p. 26-30, 1989. SAVIANI, D. Ensino público e algumas falas sobre universidade. São Paulo: Cortez: Autores Associados, 1984.

. Escola e democracia: teorias da educação, curvatura da vara, onze teses sobre educação e política. São Paulo: Cortez: Autores Associados, 1983. SCHÖN, D. Educando o profissional reflexivo: um novo design para o ensino e

aprendizagem. Porto Alegre: Artes Médicas, 2000.

SILVA, T.T. da. O trabalho docente: um processo de trabalho capitalista? In: . O que produz e o que reproduz em educação: ensayos sobre a sociología da educação. Porto Alegre: Artes Médicas, 1991.

SNYDERS, G. Escola,classe e luta de classes. São Paulo: Centauro, 1976.

SNYDERS, G . Escola,classe e luta de classes. São Paulo: Centauro, 1976 